\title{
Delayed Reduction of Nasal Bone Fractures
}

\section{Han Young Yoon, Dong Gil Han}

Department of Plastic and Reconstructive Surgery, Catholic University of Daegu School of Medicine, Daegu, Korea

No potential conflict of interest relevant to this article was reported.
Background: Nasal bone fractures are managed by closed reduction within the 2-week period, and are managed by secondary correction after this time. There is little literature on the delayed reduction for nasal bone fractures beyond the 2-week duration. We report our experience with nasal fractures, which were reduced beyond this period.

Methods: A retrospective review was performed for all patients who had undergone closed reduction of isolated nasal bone fracture. Patients were included for having undergone reduction of nasal bone fractures at or more than 2 weeks after the injury. Medical records were reviewed for demographic information, injury mechanism, fracture type, delay in treatment, and cause for delay. Postoperative outcomes were evaluated using computed tomography images.

Results: The review identified 10 patients. The average reduction time was 22.1 days. Five of patients underwent reduction between days 15 and 20, and the remaining five patients underwent reduction between days 21 and 41 . The postoperative outcomes were excellent in 8 patients and good in 2 patients.

Conclusion: Outcomes were superior for nasal fractures with displaced end plates and multiple fracture segments. Our study results appears to support delayed reduction of isolated nasal fractures in the presence of factors that delay bony reunion.

Keywords: Nasal bone / Delay / Surgery

\section{INTRODUCTION}

While most nasal bone fractures are managed by closed reduction, opinions differ on what constitutes proper timing for closed reduction of isolated nasal bone fractures. To restore the appearance and function of the nasal pyramid, some have suggested performing the reduction within 10 days of trauma for adults and within 7 days for children [1]. Occasionally, evaluation and treatment of nasal injury are delayed for unavoidable circumstances, but few studies exist on outcomes following delayed reduction, not secondary correction, of nasal bone fractures. In this study, we report postoperative outcomes in patients who underwent delayed nasal reduction.

\section{Correspondence: Dong Gil Han}

Department of Plastic and Reconstructive Surgery, Catholic University of Daegu School of Medicine, 33 Duryugongwon-ro 17-gil, Nam-gu, Daegu 42472, Korea E-mail: dghan1001@cu.ac.kr

Received April 22, 2015 / Revised May 25, 2015 / Accepted December 3, 2015

\section{METHODS}

A retrospective review was performed for all patients who underwent delayed (greater than 2 week delay from trauma) closed reduction of isolated nasal bone fractures between 2013 and 2015 by a single surgeon. A patient was included for review if preoperative and 24-hour postoperative computed tomography (CT) scans were available.

Each operation was performed using the usual technique. The fractured fragment was manipulated using Asch and Walsham forceps, a scalpel handle wrapped with Vaseline gauze for sepal deviation, and/or a Boies elevator. Upon reduction, both nostrils were stented with Merocel nasal packs (Pope Epistaxis Packing, Medtronic Xomed., Jacksonville, FL, USA) and Vaseline gauze for 24 hours.

Postoperative outcome was evaluated by a comparison between the preoperative and 24-hour postoperative CT scans. Each 
fracture was assessed and given a Stranc and Robertson classification: frontal impact group type I (FI), frontal impact group type II (FII), lateral impact group type I (LI), lateral impact group type II (LII), or comminuted fracture group (C) [2]. For each patient, postoperative outcome was assessed, whenever appropriate, for nasal deviation $(\theta)$, overall shape of nasal pyramid, malalignment of fracture, bony irregularity, and displacement [3]. Each assessment was graded as 'excellent', 'good', 'fair', 'poor', and 'very poor'. An outcome was considered 'excellent' for no degree of nasal pyramid deviation, smooth overall shape of nasal arch, and for lack of any malalignment of the fracture segment without bony irregularity or displacement. An outcome was considered 'good' for no degree of nasal pyramid deviation, smooth overall shape of nasal arch, but for mild malalignment of the fracture segment with one segment of bony irregularity or displacement (Table 1) [4].

\section{RESULTS}

The review identified 10 patients who met the inclusion criteria $(9$ males and 1 female). The mean age was 40.1 years. The mean delay between trauma and reduction was 22.1 days. Five of the reductions were performed between days 15 and 20, and the rest were performed between 21 and 41 days. Late presentation was the most common reason for delayed reduction $(n=5)$, followed by 1 case each for cervical vertebra fracture, cervical prevertebral hemorrhage, basal skull fracture, diagnosis of pulmonary tuberculosis, and pneumonia. Six patients had FI, 2 patients had LI, and 2 LII (Table 2).

The postoperative outcomes were either good or excellent for

Table 1. Grading of outcomes

\begin{tabular}{cccccc}
\hline $\begin{array}{c}\text { Degree of } \\
\text { deviation }\end{array}$ & - & - & - & $\begin{array}{c}\text { Excellent than } \\
20^{\circ}\end{array}$ & $\begin{array}{c}\text { More than } \\
20^{\circ}\end{array}$ \\
$\begin{array}{c}\text { Overall shape } \\
\text { of nasal arch }\end{array}$ & Smooth & Smooth & Smooth & Irregular & Irregular \\
$\begin{array}{c}\text { Malalignment } \\
\text { of fracture } \\
\text { segment }\end{array}$ & - & + & + & + & + \\
\hline $\begin{array}{c}\text { Bony irregularity } \\
\text { Bony }\end{array}$ & - & $\begin{array}{c}\text { One seg } \\
\text { or }\end{array}$ & $\begin{array}{c}\text { One seg } \\
\text { and }\end{array}$ & $\begin{array}{c}\text { One or } \\
\text { two and }\end{array}$ & $\begin{array}{c}\text { More than } \\
\text { two and }\end{array}$ \\
\hline \begin{tabular}{c} 
displacement \\
\hline
\end{tabular} & - & One seg & One seg & $\begin{array}{c}\text { One and } \\
\text { two }\end{array}$ & $\begin{array}{c}\text { More } \\
\text { than }\end{array}$ \\
\hline
\end{tabular}

Table 2. Summary for delayed closed reduction of nasal bone fractures

\begin{tabular}{|c|c|c|c|c|c|}
\hline No. & Sex/Age (yr) & Mechanism & Type & $\begin{array}{c}\text { Cause of } \\
\text { delayed reduction }\end{array}$ & $\begin{array}{l}\text { Delay } \\
\text { (day) }\end{array}$ \\
\hline 1 & Male/42 & Assault & LII & $\begin{array}{l}\text { DDX of pulmonary } \\
\text { Tbc }\end{array}$ & 21 \\
\hline 2 & Male/17 & Sports & $\mathrm{FI}$ & Late presentation & 16 \\
\hline 3 & Male/51 & $S / D$ & LII & Cenvical vertebra fx & 27 \\
\hline 4 & Male/55 & Traffic accident & LI & $\begin{array}{l}\text { Cervical } \\
\text { prevertebral hm }\end{array}$ & 41 \\
\hline 5 & Male/68 & $\mathrm{F} / \mathrm{D}$ & $\mathrm{FI}$ & Pneumonia & 21 \\
\hline 6 & Male/46 & Sports & LI & Late presentation & 15 \\
\hline 7 & Male/21 & Bump & $\mathrm{Fl}$ & Late presentation & 25 \\
\hline 8 & Male/24 & Bump & $\mathrm{FI}$ & Late presentation & 19 \\
\hline 9 & Male/33 & Bump & $\mathrm{Fl}$ & Late presentation & 16 \\
\hline 10 & Female/44 & $S / D$ & $\mathrm{Fl}$ & Basal skull fx & 20 \\
\hline
\end{tabular}

LII, lateral impact group type II; DDX, differential diagnosis; Tbc, tuberculosis; FI, frontal impact group type I; S/D, slip down; fx, fracture; LI, lateral impact group type I; hm, hemorrhage; F/D, fall down.

all patients. According to Stranc and Robertson classification, FI was the most common $(\mathrm{n}=6)$, with LI and LII having 2 patients each. In group FI, outcomes were 'excellent' for the 4 out of 6 patients whose reductions were performed between days 15 and 20 (Fig. 1). The remaining two patients underwent reduction after 3 weeks and experienced 'good' outcomes (Fig. 2). In group LI, outcomes were 'excellent' regardless of delays in reduction, despite one of the reductions having been performed 41 days after trauma (Fig. 3). In group LII, outcomes were 'excellent' for both patients despite the reductions having been performed at 3 weeks after trauma (Table 3, Figs. 4, 5).

\section{DISCUSSION}

The nose is susceptible to trauma due to its projection on the central face, which is important from the perspective of aesthetics. The timing of nasal bone reduction is important for the restoration of appearance and function of the nasal pyramid. Because the nasal bone is membranous, fracture sites undergo early union with fibrous adhesion. As such, reductions delayed by more than two weeks are believed to be difficult or impossible and requires secondary correction with an osteotomy [5].

Opinions differ regarding the proper timing for closed reduction of isolated nasal bone fractures. In those cases where patients 
Table 3. Types of fracture and outcomes

\begin{tabular}{cccl} 
Type & Septal deviation & Days of delay & Result \\
$\mathrm{FI}$ & - & 16 & Excellent \\
$\mathrm{FI}$ & + & 16 & Excellent \\
$\mathrm{FI}$ & - & 19 & Excellent \\
$\mathrm{FI}$ & - & 20 & Excellent \\
$\mathrm{FI}$ & + & 21 & Good \\
$\mathrm{FI}$ & - & 25 & Good \\
$\mathrm{LI}$ & + & 15 & Excellent \\
$\mathrm{LI}$ & - & 41 & Excellent \\
$\mathrm{LII}$ & - & 21 & Excellent \\
LII & + & 27 & Excellent \\
\hline
\end{tabular}

FI, frontal impact group type I; LI, lateral impact group type I; LII, lateral impact group type II
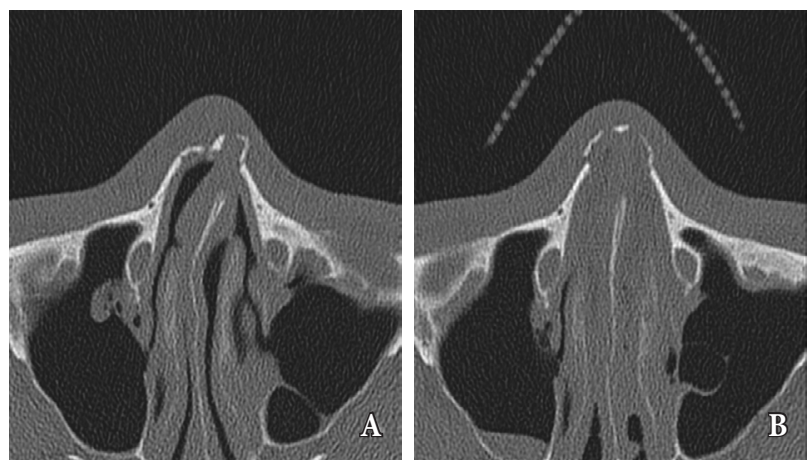

Fig. 1. In this late-presentation patient with a type-I frontal impact fracture (Case 9), closed reduction was performed 16 days after injury. (A) Preoperative computed tomography (CT) image shows displaced end plate, relatively minimal contact with marginal bony surface, and minimal septal deviation. (B) Postoperative CT image shows smooth arch contour without any nasal pyramid deviation or malalignment.
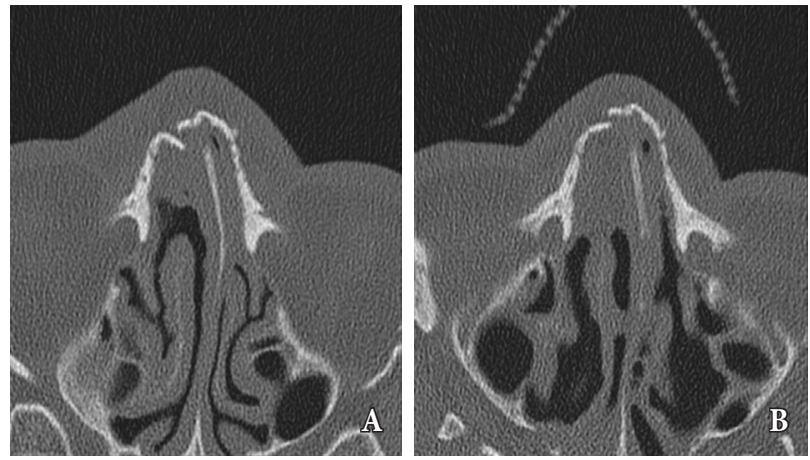

Fig. 2. In this 68-year-old patient with fall injury (Case 5), the treatment of nasal fracture was delayed due to a prolonged episode of nosocomial pneumonia. The type-I frontal impact fracture was reduced 21 days after the initial injury. (A) Preoperative computed tomography (CT) image shows minimally displaced end plate, proper contact to the marginal bony surface, minimal septal deviation, but with an interlocked fracture segment on the right lateral wall. (B) Postoperative CT image shows smooth arch contour without any nasal pyramid deviation. Mild malalignment is present, with a displaced segment.
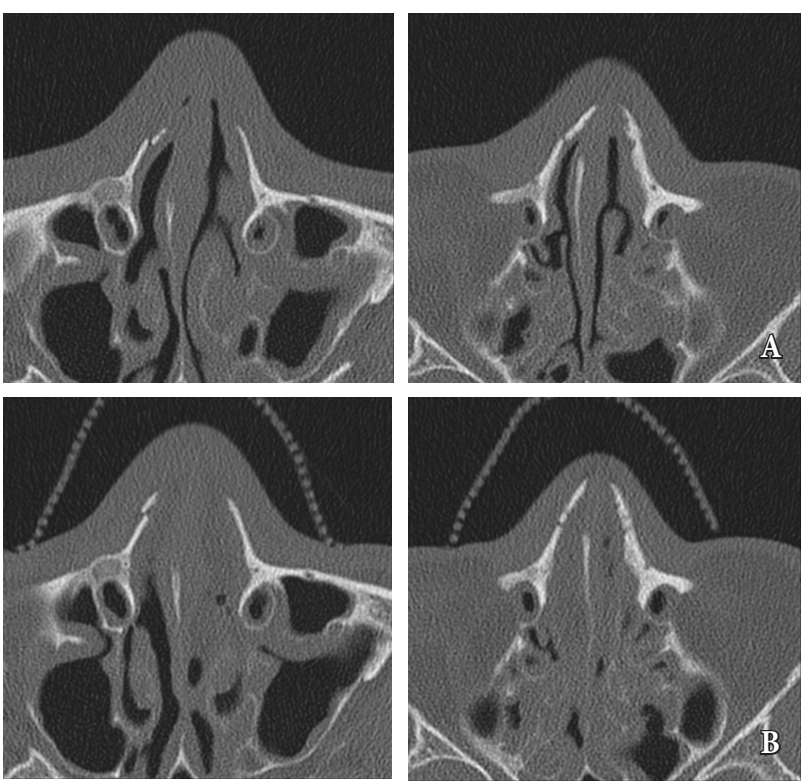

Fig. 3. In this patient with motor vehicle collision injury (Case 4), the treatment of nasal fracture was delayed due to prevertebral hemorrhage. The type-I lateral impact fracture was reduced at 41 days. (A) Preoperative computed tomography (CT) image shows displaced end plate, less contact with the marginal bony surface, and minimal septal deviation. (B) Postoperative CT image shows smooth arch contour without any nasal pyramid deviation or malalignment.
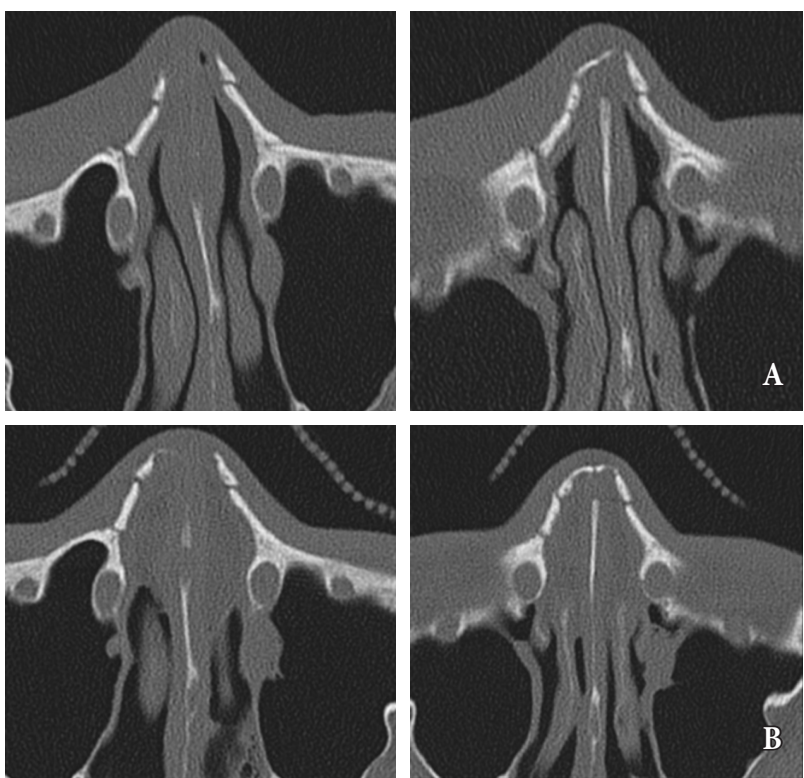

Fig. 4. This patient was injured during an altercation (Case 1), and the treatment of nasal fracture was delayed due to the diagnosis of active tuberculosis. The type-II lateral impact fracture was reduced at 21 days. (A) Preoperative computed tomography (CT) image shows multiple segmental fractures, displaced end plate, less contact with the marginal bony surface, and zero septal deviation. (B) Postoperative CT image shows smooth arch contour without any nasal pyramid deviation or malalignment. 

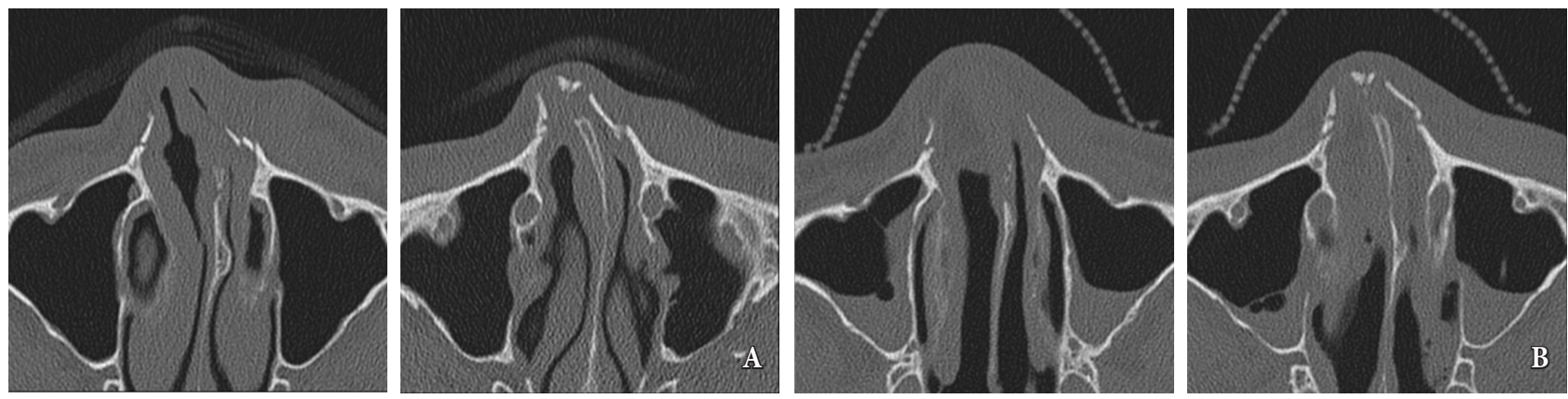

Fig. 5. This patient suffered a fall injury (Case 3), and the treatment of nasal fracture was delayed because of the need to stabilize the cervical spine because of the vertebral fracture. The type-II lateral impact fracture was reduced at 27 days. (A) Preoperative computed tomography (CT) image shows multiple segmental fractures, displaced end plate, less contact with the marginal bony surface, and minimal septal deviation. (B) Postoperative CT image shows smooth arch contour without any nasal pyramid deviation or malalignment.

present within 6 hours of trauma, nasal fractures should be reduced immediately-before significant swelling sets in. If soft tissue swelling has already set in and masks the bony outline, the fracture should be reassessed in 3 to 4 days [6]. An alternate management approach is to reduce fractures within 10 days after trauma for adults and within 7 days for children [7], as early treatment of nasal fractures are associated with improved outcomes and fractures can be reduced satisfactorily up to two weeks after trauma $[8,9]$. In certain situations, however, reductions of nasal fractures can be delayed by late presentation or by the presence of concomitant medical conditions that prohibit prompt treatment. In the first few days following facial trauma, soft tissue edema may mask other signs and symptoms of nasal bone fracture, and patients may not become cognizant of the fracture until the swelling has subsided. Occasionally, patients may present with concomitant neurosurgical or medical issues which prohibit timely reduction of the nasal fracture. For such patients, reductions are avoided in favor of secondary correction.

Our study is a review on 10 patients for whom nasal fractures were reduced primarily despite the fact that their nasal fractures were more than 2 weeks out from the day of trauma. The reductions were delayed for a number of reasons. Delayed presentation was the most common reason, with half of the patients presenting more than 2 weeks after trauma. Reductions were delayed for the remaining half of study patients because of the severity of concomitant conditions such as cervical vertebra fracture, cervical prevertebral hemorrhage, pneumonia, and active tuberculosis. In this latter group, nasal fractures were reduced as soon as the concomitant injuries or medical issues had been adequately addressed.

The longest delay in reduction was 41 days in a patient with cervical prevertebral hemorrhage, and the reduction was only performed after the hemorrhage was addressed and the patient was medically stable. In this patient, preoperative CT images revealed a type-I lateral impact fracture with minimal septal deviation and displaced end plate without contact to marginal bony surface (Fig. 3). Despite the extreme delay, the closed reduction was successful with great satisfaction of the patient.

In patients with type-II lateral impact fractures, end plates were completely displaced without contact to the marginal bony surface, multiple segmental wall fractures, and minimal septal deviation. Postoperative CT studies demonstrated excellent outcomes despite reductions being performed more than 3 weeks after trauma (Figs. 4, 5).

In the 8 excellent outcome cases, there were relatively large fracture sites, greater displacement of end plate of fracture, and more multiple segmental fractures. These factors probably contributed to freedom of movement and delayed fibrous union and, ultimately, allowed for satisfactory outcomes despite the delayed treatment. Conversely, fractures with minimal displacement will be more likely to undergo fibrous union at an earlier period (i.e., within the two weeks after injury).

In previous studies, patient satisfaction was higher for minimal-to-mildly displaced fractures than for largely displaced frac- 
tures, if reductions were performed within proper times [10]. With regard to our experience, it appears that delayed closed reduction can yield satisfactory outcomes in patients with isolated nasal fractures for whom early reduction was not possible, especially in those patients with largely displaced fractures. Despite the small sample number and lack of long-term follow up, our study results support delayed reduction of isolated nasal fractures with large displacement within the two-to-four week period.

\section{REFERENCES}

1. Rohrich RJ, Adams WP Jr. Nasal fracture management: minimizing secondary nasal deformities. Plast Reconstr Surg 2000;106:266-73.

2. Stranc MF, Robertson GA. A classification of injuries of the nasal skeleton. Ann Plast Surg 1979;2:468-74.

3. Motomura H, Muraoka M, Tetsuji MY, Ozawa MT, Nose MK.
Changes in fresh nasal bone fractures with time on computed tomographic scans. Ann Plast Surg 2001;47:620-4.

4. Lee BM, Han DG. Acute bone remodeling after reduction of nasal bone fracture on computed tomography imaging. Arch Craniofac Surg 2014;15:63-9.

5. Lee KS, Park JB, Song SH, Oh SH, Kang NH. delayed reduction of facial bone fractures. Arch Craniofac Surg 2013;14:119-23.

6. Pollock RA. Nasal trauma: pathomechanics and surgical management of acute injuries. Clin Plast Surg 1992;19:133-47.

7. Ridder GJ, Boedeker CC, Fradis M, Schipper J. Technique and timing for closed reduction of isolated nasal fractures: a retrospective study. Ear Nose Throat J 2002;81:49-54.

8. Staffel JG. Optimizing treatment of nasal fractures. Laryngoscope 2002;112:1709-19.

9. Goode RL, Spooner TR. Management of nasal fractures in children: a review of current practices. Clin Pediatr (Phila) 1972;11:526-9.

10. Yilmaz MS, Guven M, Varli AF. Nasal fractures: is closed reduction satisfying? J Craniofac Surg 2013;24:e36-8. 